Article

\title{
Comparative Study on Matching Methods for the Distinction of Building Modifications and Replacements Based on Multi-Temporal Building Footprint Data
}

\author{
Martin Schorcht*(D), Robert Hecht (D) and Gotthard Meinel (D) \\ Leibniz Institute of Ecological Urban and Regional Development, 01217 Dresden, Germany; \\ r.hecht@ioer.de (R.H.); g.meinel@ioer.de (G.M.) \\ * Correspondence: m.schorcht@ioer.de
}

check for

updates

Citation: Schorcht, M.; Hecht, R.;

Meinel, G. Comparative Study on Matching Methods for the Distinction of Building Modifications and Replacements Based on Multi-Temporal Building Footprint Data. ISPRS Int. J. Geo-Inf. 2022, 11, 91. https://doi.org/10.3390/ ijgi11020091

Academic Editor: Wolfgang Kainz

Received: 9 December 2021

Accepted: 25 January 2022

Published: 27 January 2022

Publisher's Note: MDPI stays neutral with regard to jurisdictional claims in published maps and institutional affiliations.

Copyright: (C) 2022 by the authors. Licensee MDPI, Basel, Switzerland. This article is an open access article distributed under the terms and conditions of the Creative Commons Attribution (CC BY) license (https:// creativecommons.org/licenses/by/ $4.0 /)$.

\begin{abstract}
We compare different matching methods for distinguishing building modifications from replacements based on multi-temporal building footprint geometries from 3D city models. Manually referenced footprints of building changes were used to determine which thresholds are suitable for distinction. In addition, since the underlying LoD1 (Level of Detail 1) data is highly accurate, randomly generated position deviations were added to allow for transferability to less well-matched data. In order to generate a defined position deviation, a novel method was developed. This allows determination of the effects of position deviations on accuracy. Determination of these methods' suitability for manipulation of data from sources of different levels of generalization (cross-scale matching) is therefore not the focus of this work. In detail, the methods of 'Common Area Ratio', 'Common Boundary Ratio', 'Hausdorff Distance' and 'PoLiS' (Polygon and Line Segment based metric) were compared. In addition, we developed an extended line-based procedure, which we called 'Intersection Boundary Ratio'. This method was shown to be more robust than the previous matching methods for small position deviations. Furthermore, we addressed the question of whether a minimum function at PoLiS and Hausdorff distance is more suitable to distinguish between modification and replacement.
\end{abstract}

Keywords: building change detection; matching algorithms; vector data; footprints; position deviation

\section{Introduction}

\subsection{Motivation}

The growing availability of high-resolution geospatial data, and in particular those containing individual buildings, has led to the increasing use of such data in diverse fields [1-3]. Changes in building stock are of particular interest for many applications, as they indicate the impact of past development in a given context [4-6]. Data on such changes contribute to our general understanding: it can be used as input data for forecasting models and generally helps decision-making on land use [7]. Spatially precise and up-to-date city models can be created using remote-sensing data, such as aerial/satellite images or point clouds [8,9]. By classifying data, buildings can be recognized as such by their image information or structure, enabling changes to be tracked at the level of individual objects [10-12]. Object recognition is performed using LiDAR point clouds, resulting in derivation of vector geometries of buildings [13]. Depending on the sampling rate of the sensor (point density), there are positional offsets in the derived vector geometries. Therefore, vector-based change detection is important for many types of primary data, whether automated or manually surveyed geometries.

Several studies have investigated change detection using different generalized input products [14-19]. By combining such products with cadastral information it is possible to significantly increase the strength and usefulness of models [20-22]. However, even building data from one single provider can vary over time in terms of the chosen geometry 
or modelling of building parts, which may result in extensive non-real changes [23]. Official providers are also constantly improving their data models and surveying processes, not only to offer better quality and more accurate data, but also to meet the growing demands of customers and to create a harmonized data basis to enable national monitoring [24-27]. Although the data has certainly improved over time in many respects, any change in the acquisition process can result in non-real changes, which are rarely documented in the data itself [28].

Monitoring of the building stock over time requires a differentiated analysis of changes, such as new construction, demolition, replacement or building modification (e.g., partial demolition or extension). However, it is especially difficult to distinguish between modified and replaced buildings, since in each case a change in geometry has happened. Spatially accurate change analysis is increasingly being carried out solely on the basis of vector geometries, such as surveyed footprints from land cadasters or 3D buildings from Levelof-Detail (LoD) city models [29-31]. In the meantime, such LoD datasets are regularly updated and can therefore be used for monitoring [32].

\subsection{Aim of the Study}

When comparing vector geometries of building data, the Common-Area-Ratio $(C A R)$ [33-35] or the Common-Boundary-Ratio (CBR) [36,37] are used to identify matching object-pairs on the basis of $2 \mathrm{D}$ polygons. These methods have widely varying accuracies depending on the underlying data and the subject under investigation [38]. In addition, metrics such as Hausdorff Distance (HDD) [39] or a comparison of Polygon or Line Segments (PoLiS) [14] are used to determine changes in building polygons. Avbelj's paper [14] has already examined how translation, rotation and scaling affect the $H D D$, PoLiS and Chamfer distance.

In this paper, we investigate how well these methods are suited for distinguishing modified and replaced buildings based on vector geometries, and how position deviations affect the results. In some cases, multiple intersection areas occur for a pair of objects, where statements about the entire object-pair are insufficient. Therefore, we have developed an extended line-based matching method, with which multiple intersection areas can be evaluated individually, which we have called Intersection Boundary Ratio (IBR).

In addition, an important question is how position deviations affect the accuracy of matching procedures. Therefore, we have developed a novel method to generate defined position deviations.

In particular, we consider the following three questions:

- Research Question 1 (RQ1): What accuracies and threshold can be expected for the CAR, $C B R, H D D$, PoLiS and IBR matching procedures to distinguish between modified and replaced buildings when detecting changes in building footprints? In case of $C A R, C B R$ and $I B R$, we expect thresholds between 50-70\% based on Rutzinger's assumptions [38].

- $\quad$ Research Question 2 (RQ2): When distinguishing between modified and replaced buildings, is the minimum function more appropriate than the maximum function for the HDD and PoLiS metrics? Since modified buildings do not match well anyway, depending on the extent of the modification, we assume that a minimal function is better to distinguish between modified and replaced buildings.

- $\quad$ Research Question 3 (RQ3): How do position deviations affect accuracy? We assume that the $C B R$ and $I B R$ matching procedures are more likely to produce inaccurate results for larger position deviations, since the tolerance values of these methods lead to mismatches more often.

\section{Materials and Methods}

In this section, we first show the general workflow of the methodology of our study. Then we provide an overview of the input data used, the different types of changes and the matching methods investigated. In addition, we show how the optimal thresholds were 
determined, and how the position deviation of the polygons was generated. The workflow diagram serves as orientation for the structure of this study (Figure 1).

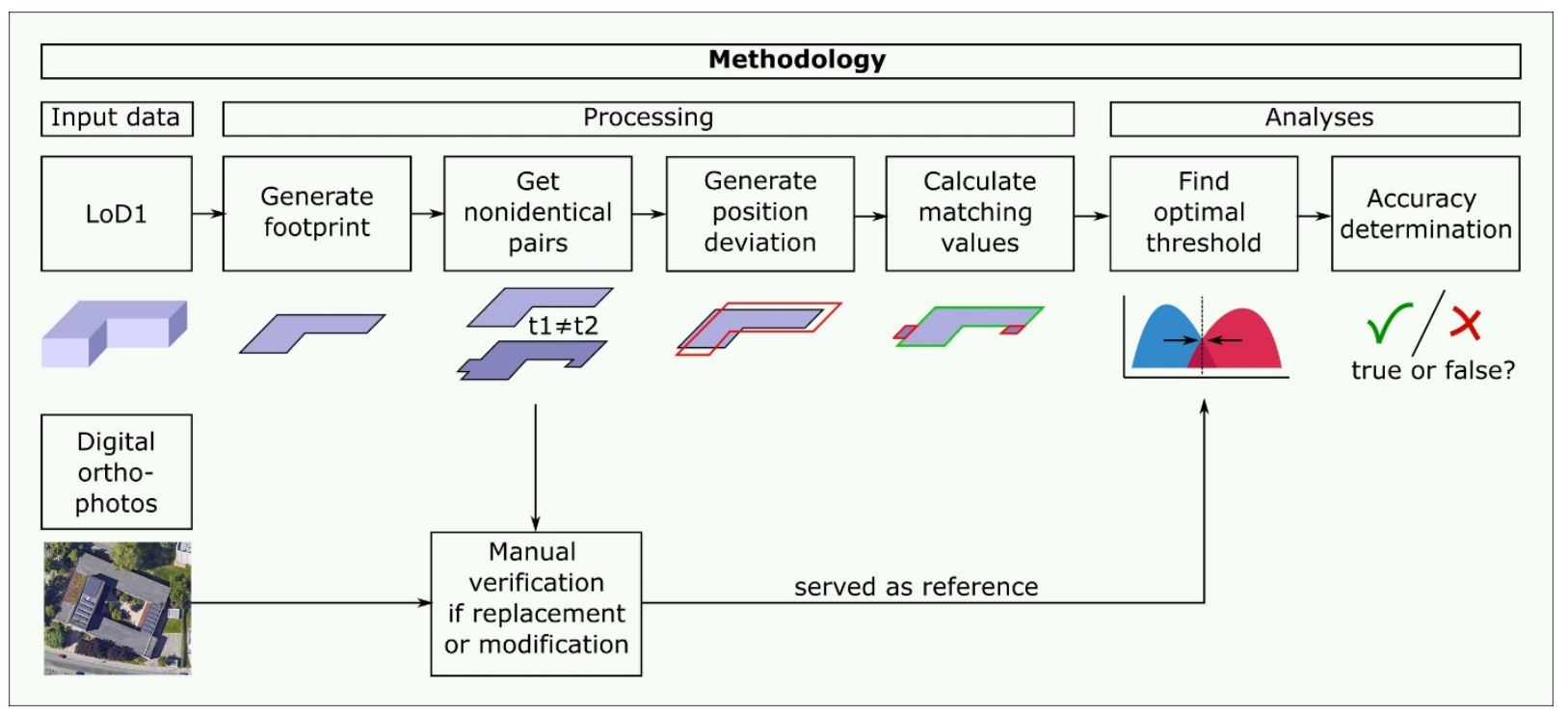

Figure 1. Methodology of this study.

\subsection{Case study and Input Data}

For our study, we used LoD1 (Level of Detail 1) data in CityGML format for the city of Hamburg as the data basis. In the case of LoD1 data, buildings are represented as block geometries; i.e., no details, such as the shape of the roof or gables, are shown. The data only contain the extruded footprint of a building [28]. The LoD1 data used are from the years 2015 and 2018 and are freely accessible (url: https://transparenz.hamburg.de/, accessed on 15 November 2021). In addition, airborne orthophotos of different points in time from Google Earth (url: https:/ / www.google.com/intl/de_de/earth/, accessed on 16 November 2021) were used to identify building changes. This manually determined change information was used as reference data.

In Germany, the Zentrale Stelle Hauskoordinaten und Hausumringe $(\mathrm{ZSHH})$ is the public agency responsible for the distribution of building coordinates and footprints. Since 2015, it has issued annually updated LoD1 datasets for the entire federal territory. In most cases, the building footprints from the German digital cadastral map (Amtliche Digitale Liegenschaftskarte) form the basis for generating these LoD1 buildings; a high positional accuracy of $\pm 1 \mathrm{~m}$ makes this a well-suited basis for our study. The buildings were extruded by means of height measurements from a laser scanner or photogrammetric survey, whereby a height accuracy of $\pm 5 \mathrm{~m}$ can be expected [40].

In our case, we only use the footprints to allow transferability to 2D datasets. However, it would be conceivable to evaluate the height information in a subsequent step, which would enable analyses of floor changes in the case of matching footprints. The evaluation of the building function would also be conceivable, but since this is not always assigned, we do not include it in this analysis.

Since we focused our study on the distinction between building modification and replacement, only building polygons of nonidentical object-pairs were examined. We did not focus on the distinction between changed (modification or replacement) and unchanged building pairs. Therefore, in order to identify nonidentical object-pairs, we chose a simplified approach. If the line segment points of a building were farther than $1 \mathrm{~m}$ from the line segments of the associated building, the pair of buildings was considered as nonidentical. Thus, in rare cases, nonidentical pairs of objects were actually unchanged buildings for which minor position corrections had been made. However, since we only 
wanted to distinguish between replaced and modified buildings, these corrected building pairs were considered as modifications

The 2015 dataset contained 72,675 objects, and the 2018 dataset 77,301 objects. A total of 2285 nonidentical object-pairs were examined in this study, indicating a position deviation of at least $\pm 1 \mathrm{~m}$ for identical object-pairs. Figure 2 shows the study area, with the investigated nonidentical object-pairs highlighted in pink. These pairs of objects represent either a demolished building that has been replaced with a new construction or the same building that has been partially extended/deconstructed (modification or in rare cases position correction). For each nonidentical pair of objects, aerial images were used to determine whether this represented a replaced or modified building, which served as a reference.

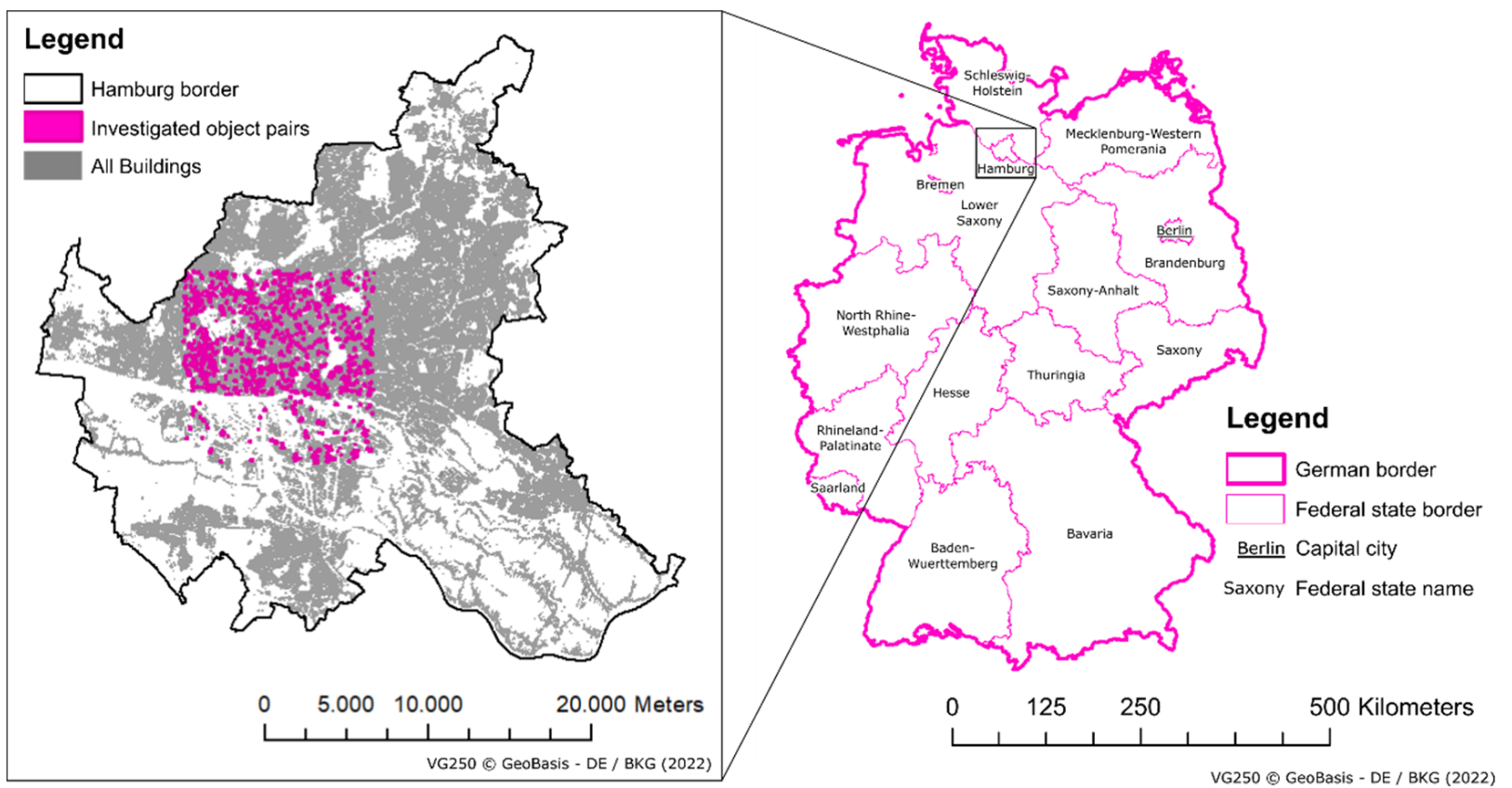

Figure 2. Study area, city of Hamburg (2015-2018); investigated intersection polygons of nonidentical object-pairs $(n=2285)$ highlighted in pink on the left side.

\subsection{Types of Building Changes}

In this investigation, vector geometries of two 2D datasets (here footprints of LoD1) representing different points in time (T1, T2) were analysed in order to identify changes.

The different types of building changes are exemplarily shown in Table 1. For the reference objects, only replacement and modification were determined.

\subsection{Matching Procedures}

Here the matching procedures are briefly presented, with only the method we developed being described in some detail.

\subsubsection{Common Area Ratio (CAR)}

In previous studies, pairs of objects to be examined were often identified in a preprocess, based on the degree of overlap, in order to examine them more in-depth in further steps $[34,35,41]$. For this purpose, for each object-pair $O_{i j}$ the respective overlap ratio is calculated, and the lower of these two values is selected:

$$
\operatorname{CAR}\left(O_{i j}\right)=\min \left(\frac{A_{C, i} \cap A_{R, j}}{A_{C, i}}, \frac{A_{C, i} \cap A_{R, j}}{A_{R, j}}\right)
$$


where $A_{C, i}$ are the areas of the objects in the first dataset, and $A_{R, j}$ those of the second. The intersection of both is represented as $A_{C, i} \cap A_{R, j}$. In the case of m:n (many to many) changes, $A_{C, i}$ or $A_{R, j}$ can also consist of a set of areas of several objects $\left.\left(<A_{G, m}, \ldots, A_{G, n}\right\rangle\right)$. In this case, we checked if the dissolved polygons had a higher matching degree and then selected the better-matching value. The range of values is from 0 to 1 , where 0 corresponds to no match (0\%) and 1 to a complete match $(100 \%)$. A maximum function is not recommended here, because a value of $100 \%$ only indicates that one surface is within the other.

Table 1. Types of building changes.

\begin{tabular}{|c|c|c|c|}
\hline Title 1 & Time 1 & Time 2 & Time $1 \cap$ Time 2 \\
\hline $\begin{array}{l}\text { New construction } \\
(\varnothing: \mathrm{n})\end{array}$ & $\varnothing$ & & \\
\hline $\begin{array}{l}\text { Demolition } \\
\text { (n:Ø) }\end{array}$ & & $\varnothing$ & \\
\hline $\begin{array}{c}\text { Replacement } \\
\text { (demolition and } \\
\text { new construction) }\end{array}$ & & & \\
\hline $\begin{array}{c}\text { Modification } \\
\text { (extension or } \\
\text { deconstruction) }\end{array}$ & & & \\
\hline
\end{tabular}

\subsubsection{Common Boundary Ratio (CBR)}

Similar to the $C A R$, the degree of matching polygon lines $\left(L_{C, i}, L_{R, j}\right)$ can be evaluated for each object-pair. Here the segments at both points in time are examined to determine whether they coincide within a certain a tolerance range $(\varepsilon)$. To do this, the segments of the objects of the first time-point are intersected with those of buffered segments $(B u f f e r(L, \varepsilon))$ of the second time-point and vice versa. In the old dataset, buildings often incorrectly included garages, elongated underpasses or overpasses, which led to poor matching results even when the overlapping area described the same building. In contrast to the $C A R$, it is better to determine a maximum function, since the maximum function provides higher values in the case of modifications or data corrections:

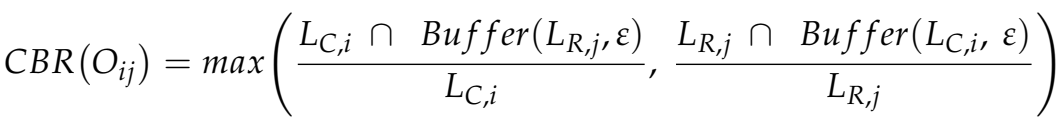

where $L_{C, i}$ are the polygon lines in the first dataset and $L_{R, j}$ those of the second. Those line segments of the first dataset that are within the buffered segments of the second dataset are described as $L_{C, i} \cap \operatorname{Buffer}\left(L_{R, j}, \varepsilon\right)$ and vice versa. They represent the segment parts that match one another. Moreover, in the case of m:n changes, $L_{C, i}$ or $L_{R, j}$ can consist of a set of lines of several objects $\left(\left\langle L_{G, m}, \ldots, L_{G, n}\right\rangle\right)$. In this case the segments of the dissolved polygons should be used. Again, the range of values is from 0 to 1 , where 0 corresponds to no match $(0 \%)$ and 1 to a completely matching object-pair $(100 \%)$. Examples of $C A R$ and $C B R$ are shown in Figure 3. 


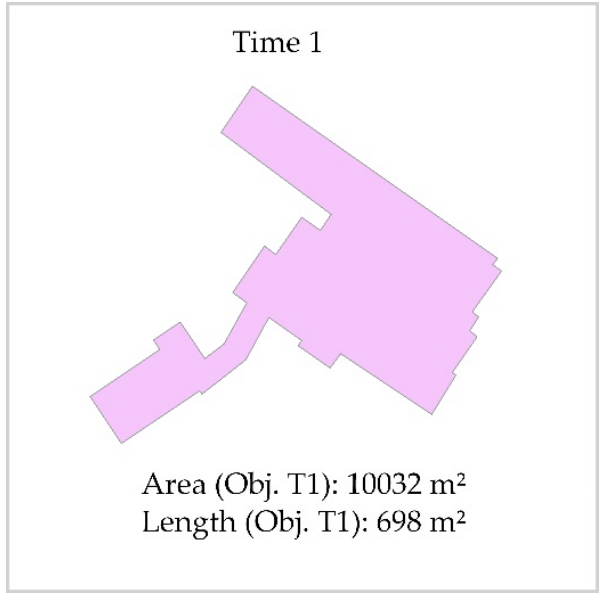

(a)

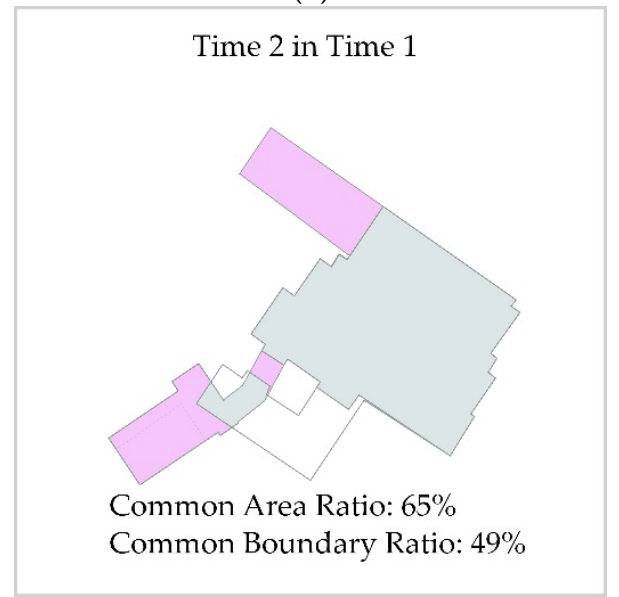

(c)

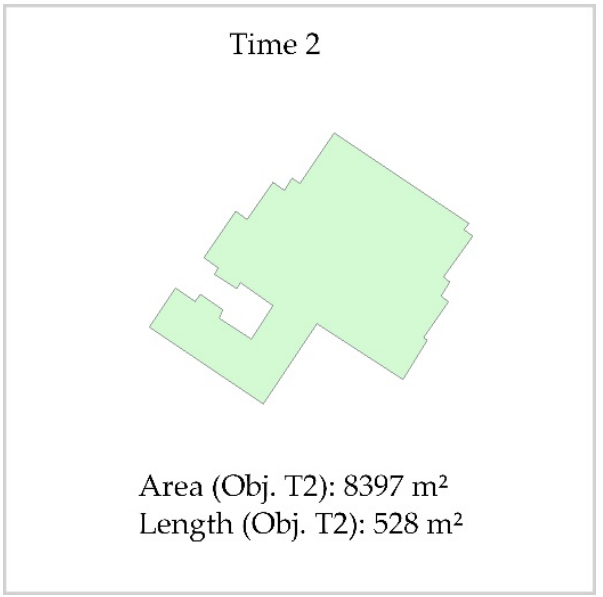

(b)

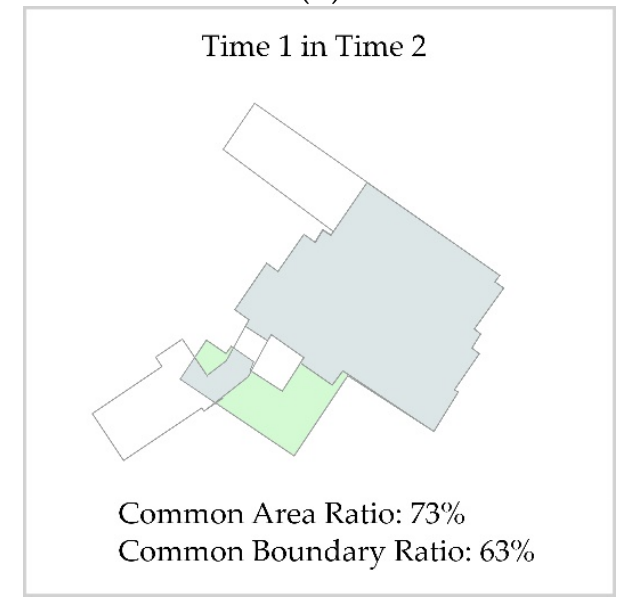

(d)

Figure 3. Examples of Common Area Ratio $(C A R)$ and Common Boundary Ratio $(C B R)$ for two footprints from different time points: (a) building at time 1 ; (b) building at time 2; (c) CAR and CBR of T1, T2; (d) CAR and CBR of T2, T1. Violet indicates the old area, green is the new area, and gray is the overlapping area.

\subsubsection{Intersection Boundary Ratio (IBR)}

The $I B R$ is similar to the $C B R$ with the difference that the overlapping intersection areas are evaluated individually. This improves accuracy because in some cases more complex changes have occurred; for example, objects may have been partially deconstructed on one side and extended on the other (Figure 3). The situation becomes even more difficult when these areas overlap each other, because then the area of intersection has both a changed and an unchanged portion.

For this purpose, we have extended the $C B R$ analysis to consider intersection areas individually. Each intersection polygon ( $\left.I_{i j k}=A_{E, k} \mid A_{E, k} \in A_{C, i} \cap A_{R, j}\right)$ is examined to determine which of its segments $\left(L_{E, k}\right)$ matches the outlines of both original objects $\left(L_{C, i}\right.$ and $\left.L_{R, j}\right)$. In order to be able to take position deviations into account, buffering is also applied here as a tolerance range $(\varepsilon)$ :

$$
\operatorname{IBR}\left(I_{i j k}\right)=\frac{L_{E, k} \cap \operatorname{Buffer}\left(L_{C, i}, \varepsilon\right) \cap \operatorname{Buffer}\left(L_{R, j}, \varepsilon\right)}{L_{E, k}}
$$

In contrast to $C A R$ or $C B R$ (both of which consider a pair of objects as a whole), IBR allows for a more differentiated analysis of each individual intersection area of an objectpair. The $I B R$ value is $1(100 \%)$ if all line segments of an intersection area lie within the 
buffered segments of the original object from both time points. As with the other two methods, if m:n changes occur, the dissolved intersecting areas can be examined to obtain better-matching values.

Figure 4 shows not only that intersection areas can be analyzed individually, but also that the percentage of overlap can be considerably higher than with $C B R$ or $C A R$. It should be pointed out that the results of $I B R$ and $C B R$ only differ when extension and deconstruction occur together.

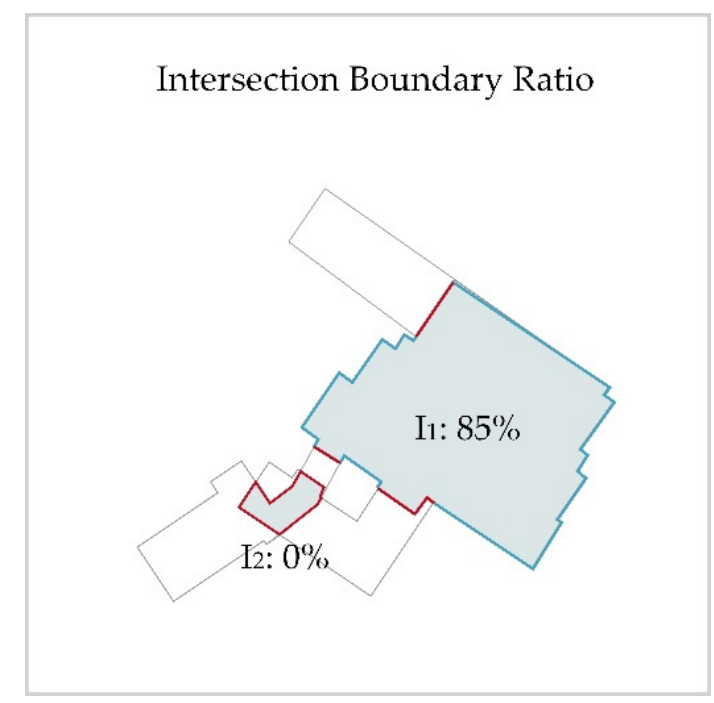

Figure 4. Example of Intersection Boundary Ratio (IBR) calculated separately for each area of intersection $\mathrm{I}_{1}$ and $\mathrm{I}_{2}$ (same input objects $\mathrm{T} 1$ and $\mathrm{T} 2$ as in Figure 3). Blue lines show matching of line segments from T1 and T2, red lines do not match between T1 and T2, and gray is the overlapping area.

\subsubsection{Hausdorff Distance (HDD)}

The Hausdorff distance is used in many applications where the number of points in two given sets $(A, B)$ is not equal, and therefore no correspondence is given. For each pair of objects, the polygon points from the first object $\left(a_{i} \in A\right)$ and the polygon points from the second object $\left(b_{k} \in B\right)$ are taken as a given set. The directed Hausdorff distance between $\mathrm{A}$ and $B$ describes the supremum of these point sets, which is the largest distance between the points of $\mathrm{A}$ and the nearest point of $\mathrm{B}$ :

$$
\vec{h}(A, B)=\max _{a_{i} \in A} \min _{b_{k} \in B}\|a-b\|
$$

The maximum of the two suprema $(\vec{h}(A, B), \vec{h}(B, A))$ is the Hausdorff distance, which is a metric, at least in the mathematical sense, because it fulfills positive definiteness, symmetry and triangle inequality (for more detail see [39]):

$$
h(A, B)=\max (\vec{h}(A, B), \vec{h}(B, A))
$$

The minimum value is $0 \mathrm{~m}$, and the maximum value is not greater than the maximum extent of the largest building polygon in the given dataset (at least in the case of overlapping pairs of polygons).

Since in our case we wanted to know if the object-pair described the same building, we also examined the minimum function. With this, we wanted to verify if better-matching results could be achieved with modified buildings (e.g., in case of removed overpasses):

$$
h(A, B)_{\min }=\min (\vec{h}(A, B), \vec{h}(B, A))
$$


The unit of the calculated distance is that of the underlying polygons.

\subsubsection{Polygon and Line Segments (PoLiS)}

The directed PoLiS describes the mean distance of every point of one polygon $A$ $\left(a_{j} \in A, j=1, \ldots, q\right)$ to the vertexes (or points) of another polygon $B\left(b_{k} \in B, k=1, \ldots, r\right)$ per object-pair (for more details see [14]):

$$
\vec{p}(A, B)=\frac{1}{q} \sum_{a_{j} \in A} \min _{b \in \partial B}|| a_{j}-b \|
$$

The weighted sum of the two directed parameters $(\vec{p}(A, B), \vec{p}(B, A))$ is used to obtain a symmetrized and similar metric:

$$
p(A, B)=\frac{1}{2 q} \sum_{a_{j} \in A} \min _{b \in \partial B}\left\|a_{j}-b\right\|+\frac{1}{2 r} \sum_{b_{k} \in B} \min _{a \in \partial A}\left\|b_{k}-a\right\|
$$

where $q$ and $r$ are used to normalize the unequally distributed number of points of objects A and $\mathrm{B}$ to obtain a weighted average. As with $H D D$, the minimum is $0 \mathrm{~m}$, and the maximum is no wider than the widest building in the dataset. One advantage of HDD and PoLiS is that no additional parameters have to be specified, such as the tolerance range $(\varepsilon)$ as in $C B R$ and IBR.

Again, we want to examine whether the lower value of the directed parameters is more suitable to better distinguish between modifications and replacement structures:

$$
p(A, B)_{\min }=\min (\vec{p}(A, B), \vec{p}(B, A))
$$

As before, the unit is that of the underlying polygons.

Figure 5 shows that a larger building complex has been constructed over time, although the elongated sections (marked with an arrow) have not changed in reality. Applying the maximum function of HDD or weighted sum of PoLiS to this example, the objects involved would have higher distances, while using the minimum function would result in lower distances. For example, for HDD, a value of $153 \mathrm{~m}$ would be obtained for the marked object, whereas for HDDmin only $16 \mathrm{~m}$ would be obtained. By using the minimum function, modified subareas would not receive such high values and could be better distinguished from replaced buildings, which is why we also considered these adjusted parameters.

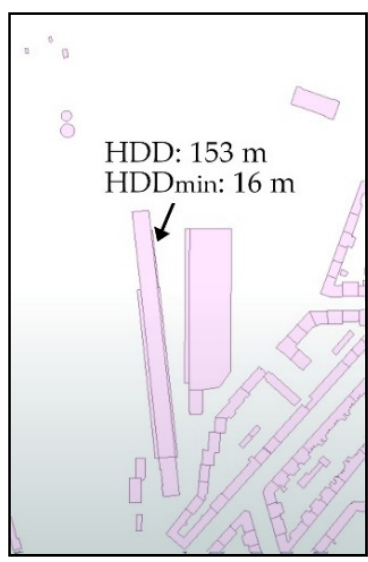

(a)

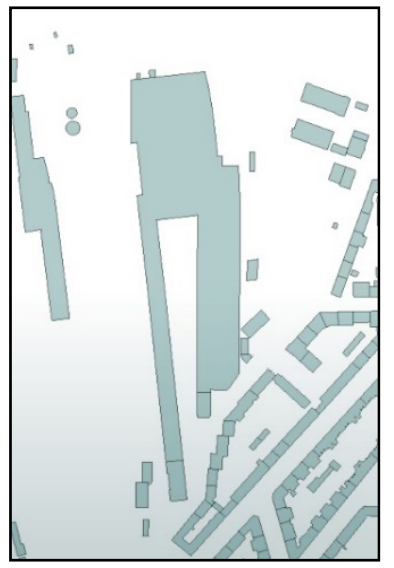

(b)

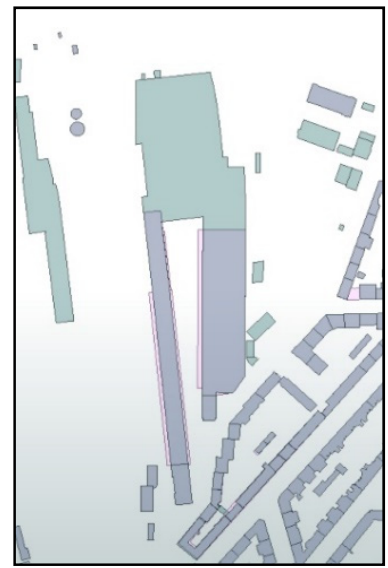

(c)

Figure 5. Example of Hausdorff Distance $(H D D)$ and the minimum function of Hausdorff Distance (HDDmin) for a large, changing building complex where the intersection areas have not changed in reality: (a) buildings at time 1; (b) buildings at time 2; (c) buildings from time 1 and time 2 are overlaid. 


\subsection{Threshold and Error Determination}

\subsubsection{Optimal Threshold}

The optimal thresholds were determined for each matching procedure, which were then used to distinguish between modified and replaced buildings (Figure 6). This was performed by an iterative approach. For each matching method, a range was determined based on the respective minimum and maximum values. Based on the given references of building changes ( $\mathrm{n}$-modified $=1359$; -replaced $=926$ ), a total error was determined for each possible threshold value within the determined range (up to one decimal place), and then the threshold value with the lowest error was selected.

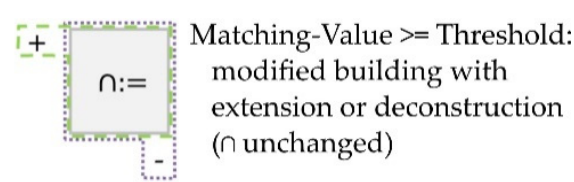

(a)

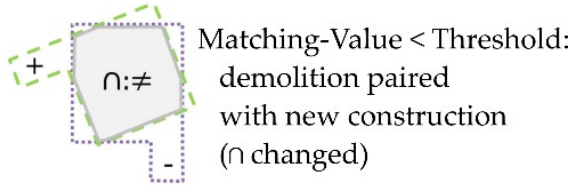

(b)

Figure 6. Schematic examples of a modified building and a replaced building: (a) modified building with unchanged intersection area; $(\mathbf{b})$ replaced building with changed intersection area.

\subsubsection{Total Error}

The total error was determined by relating the proportion of incorrectly determined building area to the total area of all buildings:

$$
\text { total error }=\frac{\text { total building area }}{\text { false determined area }} * 100 \text {, }
$$

\subsubsection{User Error}

The user error was determined by relating the area of changes determined by the matching procedure to the area of incorrectly determined buildings:

$$
\text { user } \text { error }=\frac{\text { user building area }}{\text { false determined user area }} * 100 \text {, }
$$

\subsubsection{Producer Error}

The producer error was determined by relating the area of reference changes to the area of incorrectly determined buildings:

$$
\text { producer error }=\frac{\text { reference building area }}{\text { false determined reference area }} * 100 \text {, }
$$

\subsection{Generating Position Deviations}

Since the given input data have a high positional accuracy of $\pm 1 \mathrm{~m}$, additional position deviations were added in a further step. With these simulated errors, a transferability to less well-matched datasets should be made possible; we also examined how position deviations affect the accuracy of the investigated matching methods.

For this purpose, the segments of the building polygons were shifted laterally in $0.25 \mathrm{~m}$ increments up to $\pm 5 \mathrm{~m}$. The displacement was random and followed a Gaussian normal distribution, which is why we called this procedure 'Random Bell Error Generator' (RBEG). Each building polygon was divided into several segments, whereby only segments that changed their direction by at least $20^{\circ}$ were separated. After the segments were shifted laterally with respect to their overall direction, they were extended until they intersected with the original neighboring segment to reform a closed polygon. Subsequently, resulting overlays were removed.

Figure 7 shows the process schematically on a building footprint. Figure 8, on the other hand, shows an example from the generated dataset. It should be noted that the 
random value is normally distributed, so that, although infrequent, expected displacement values can be significantly exceeded.

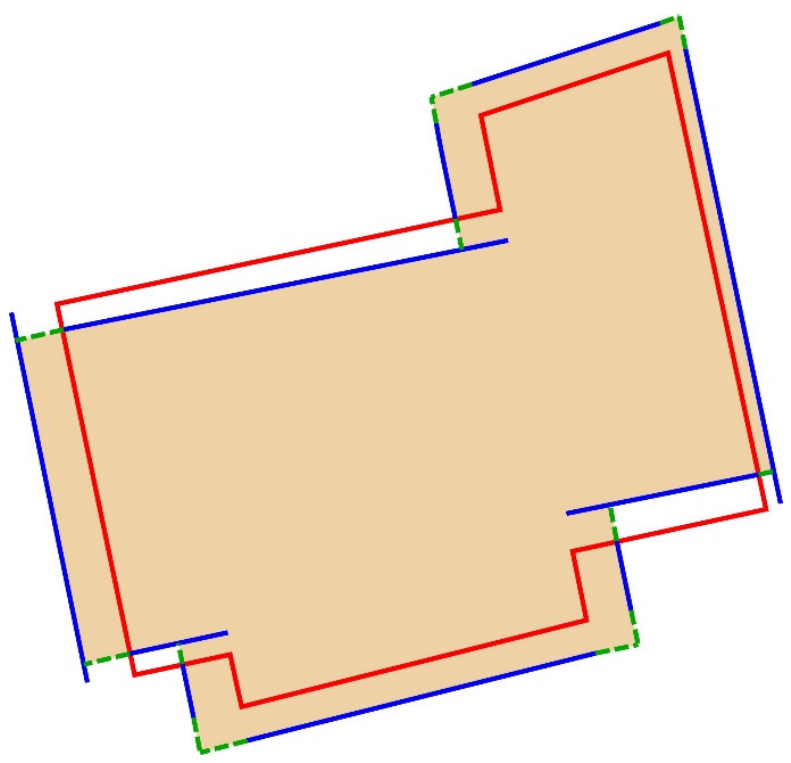

Figure 7. Schematic example of generated errors: red lines are the original polygon, blue lines are the separated and latterly shifted segments, green dotted lines are the extended lines, and the beige polygon is the newly formed polygon.

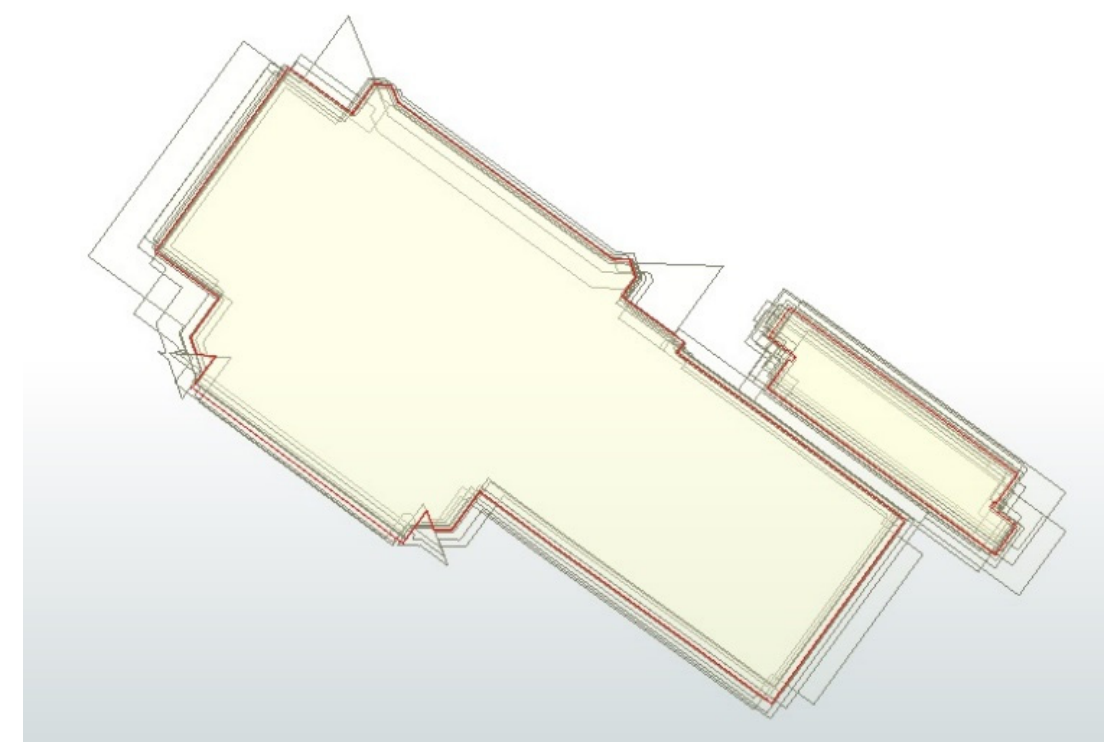

Figure 8. Example of generated position deviations, whereby the iteration steps $(0.25 \mathrm{~m}, 0.5 \mathrm{~m}, \ldots$, $4.75 \mathrm{~m}$ and $5 \mathrm{~m}$ ) are overlaid. The red lines show the original polygons.

This process was repeated ten times for each width $(0.25 \mathrm{~m}, 0.5 \mathrm{~m}, \ldots, 4.75 \mathrm{~m}$ and $5 \mathrm{~m}$ ) due to the random value generation. Subsequently, an optimal threshold value was determined from the ten datasets of each width, which in turn was used to form an average threshold value per width.

This procedure was applied to all investigated matching methods, from which could be determined to what extent positional inaccuracies affected the matching results. For the $C B R$ and $I B R$ matching methods, the buffer tolerance ranges $(\varepsilon)$ were increased according to the increasing deviation. 


\section{Results}

We reviewed the studies on CAR, CBR, PoLiS and HDD to compare pairs of objects corresponding to a replaced or modified building. This section first presents the determined distributions of replacements and modifications that resulted from the individual matching procedures. Furthermore, the respective optimal threshold values and the accuracies achieved with them are presented. Finally, it is shown to what extent position deviations affect the accuracies of the investigated matching methods.

\subsection{Distributions}

A total of 2285 nonidentical pairs of objects were included in the reference dataset, of which 1359 were modified buildings and 926 were replaced buildings. For these objectpairs, values were calculated for all investigated matching methods, whose distribution was then graphically represented in the form of histograms (Figure 9).

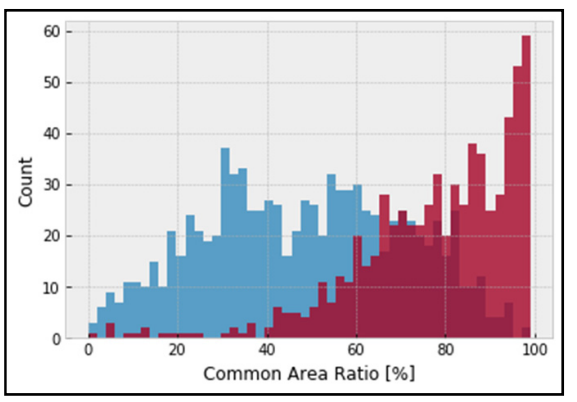

(a)

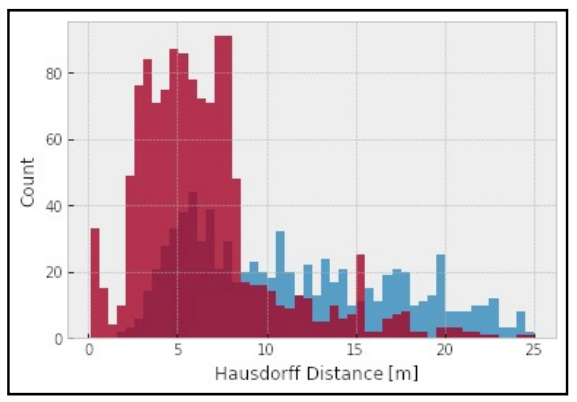

(d)

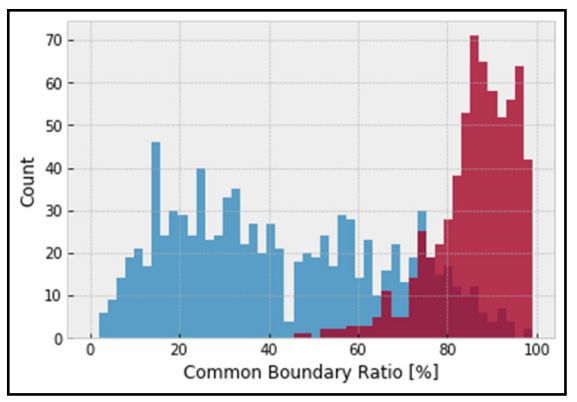

(b)

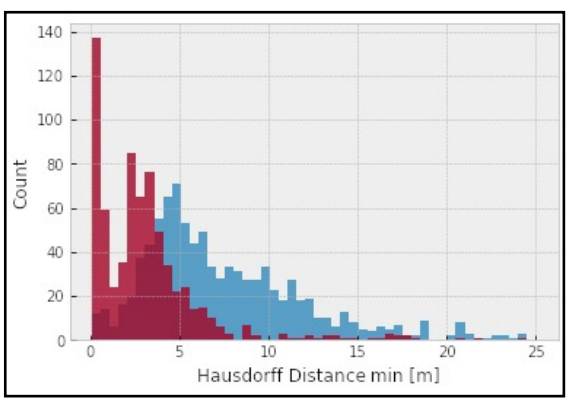

(e)

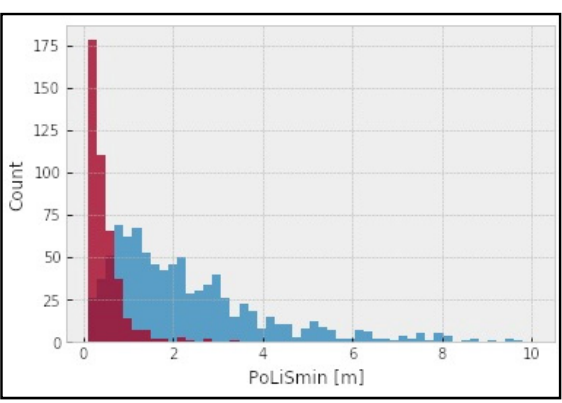

(g)

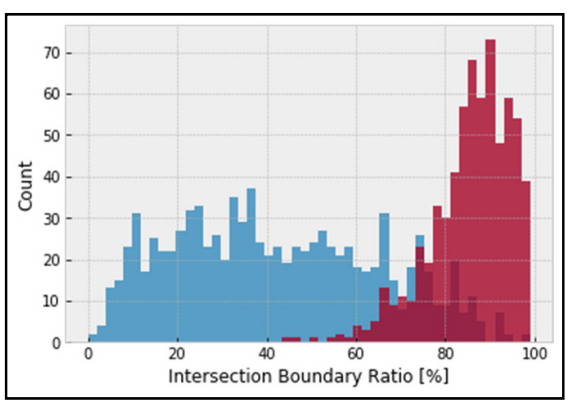

(c)

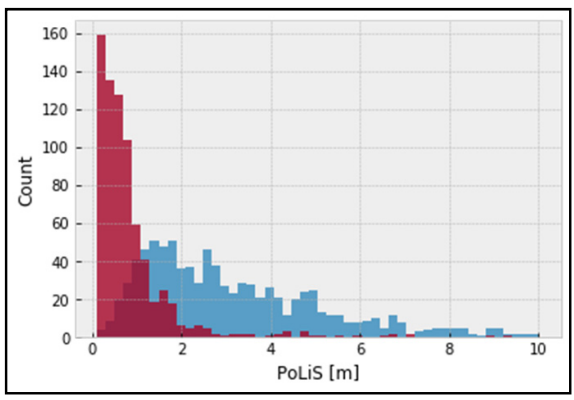

$(\mathbf{f})$

Figure 9. Histograms of the investigated matching methods: blue bars indicate modified buildings, red bars are replaced buildings, and dark red bars are the overlay of blue and red bars; (a) Common Area Ratio (CAR); (b) Common Boundary Ratio (CBR); (c) Intersection Boundary Ratio (IBR); (d) Hausdorff Distance; (e) Minimum function of Hausdorff Distance (HDDmin); (f) Polygon and Line Segments (PoLiS); (g) Minimum function of PoLiS (PoLiSmin).

In these histograms, it can be seen that for $C A R, I B R$ and $C B R$, modified buildings more often obtained higher values, and lower values are more indicative of replacement 
buildings. HDD (min) and PoLiS ( $\mathrm{min}$ ), on the other hand, show the opposite picture, with lower values indicating a modified building, and replacement buildings are more likely to be expected with increasing values. In addition, it can be seen that $C A R$ and both HDD variants have a comparatively higher overlap of building modifications and replacements, which is shown as dark red bars. It is noteworthy that the minimum function performs significantly better in the comparison of the HDD variants, whereas the two PoLiS variants show a similar distribution.

\subsection{Optimal Thresholds and Accuracies}

Based on the calculated values, the optimal thresholds for each matching procedure were determined, as described in Section 2.4.

If all of the 2285 building changes were determined as modifications, the total error would be $27 \%$. If, in contrast, all changes were determined to be replacement buildings, the total error would be $73 \%$; this is consistent for all matching methods. In Figure 10, these extrema are reversed for the matching methods with percent match rates $(C A R, C B R$ and IBR) and with distance rates (HDD, HDDmin, PoLiS and PoLiSmin) because high match rates are comparable to low distances.

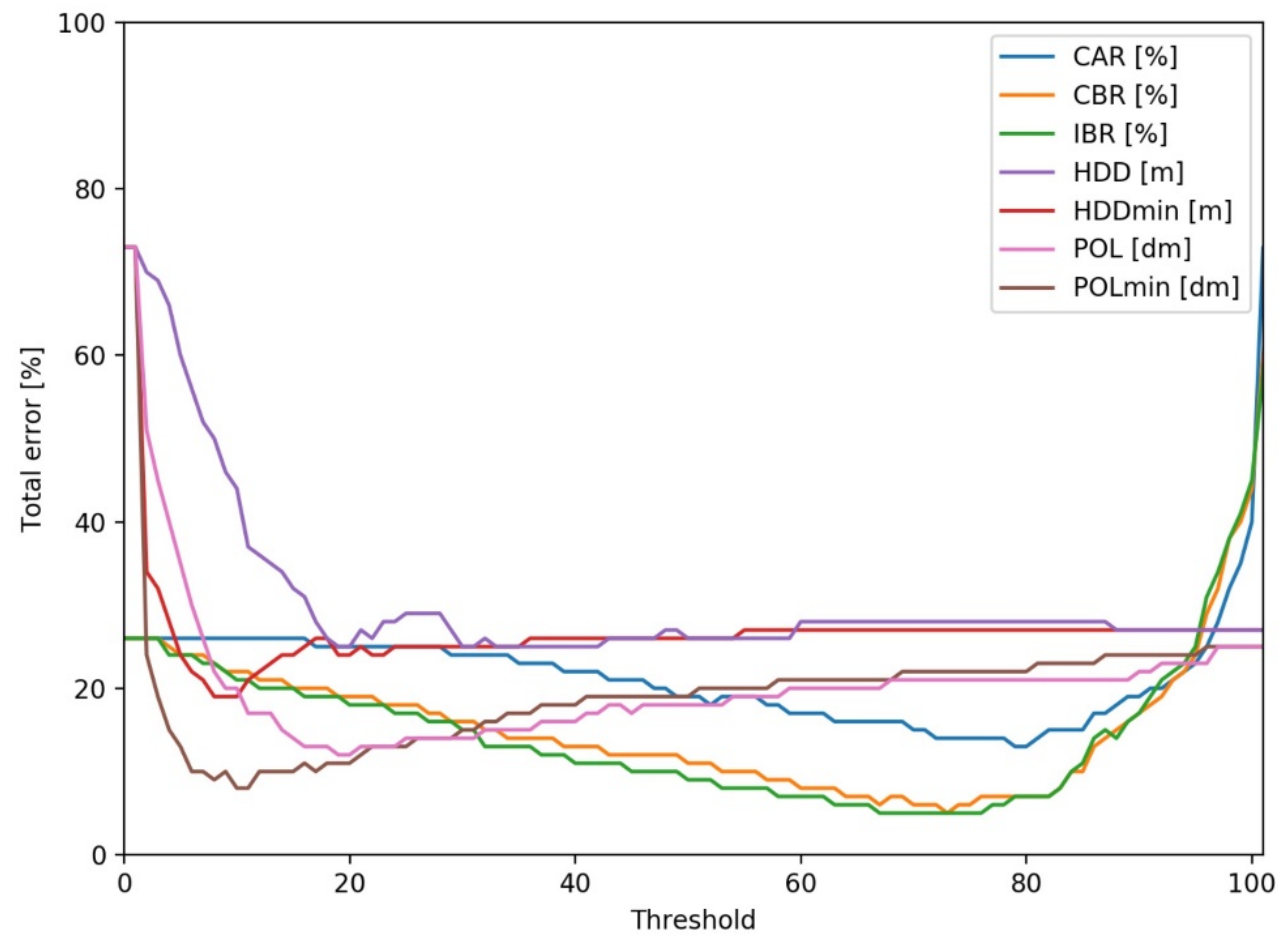

Figure 10. Overview of the determination of the optimal threshold values of all matching methods. For better comparability, the values of PoLiS (POL) and PoLiSmin (POLmin) are shown as decimeters.

The detailed results are shown in Table 2, which shows the threshold values as well as the resulting accuracies. In addition to the total error, the accuracy was also divided according to the two classes investigated (replaced or modified building). A distinction was made between area incorrectly determined in the reference data (Prod. error) vs. area incorrectly determined by the matching procedures (User error). For example, for PoLiSmin, the total error is $8.3 \%$, with $17.7 \%$ of the reference areas being incorrectly identified as replaced buildings, and $6.3 \%$ of the identified buildings being incorrect. This means that about every sixth replaced building was not recognized as such, and out of the buildings that had been determined to have been replaced, about one out of every 16 was false. 
Table 2. Thresholds and accuracies of investigated matching methods for distinguishing modified from replaced buildings based on 2285 reference areas.

\begin{tabular}{ccccccc}
\hline & \multirow{2}{*}{$\begin{array}{c}\text { Optimal } \\
\text { Threshold }\end{array}$} & $\begin{array}{c}\text { Total Area } \\
\text { Error [\%] }\end{array}$ & \multicolumn{2}{c}{ Replaced Area Error [\%] } & \multicolumn{2}{c}{ Modified Area Error [\%] } \\
\cline { 5 - 7 } & & User Error & Prod. Error & User Error & Prod. Error \\
\hline CAR & $78 \%$ & 13.0 & 6.5 & 16.9 & 27.9 & 11.6 \\
\hline CBR & $72 \%$ & 5.9 & 5.5 & 15.7 & 7.2 & 2.4 \\
\hline IBR & $74 \%$ & 5.6 & 4.4 & 12.2 & 9.0 & 3.2 \\
\hline HDD & $18.1 \mathrm{~m}$ & 25.3 & 14.9 & 38.4 & 47.9 & 20.6 \\
\hline HDDmin & $6.9 \mathrm{~m}$ & 19.1 & 9.8 & 24.8 & 38.4 & 17.0 \\
\hline PoLiS & $1.8 \mathrm{~m}$ & 12.7 & 7.5 & 20.1 & 25.7 & 10.0 \\
\hline PoLiSmin & $0.9 \mathrm{~m}$ & 8.3 & 6.3 & 17.7 & 14.1 & 4.9 \\
\hline
\end{tabular}

\subsection{Thresholds and Accuracies of Generated Deviations}

The position deviations generated with RBEG as described in Section 2.5 were examined with the different matching methods. Since the minimum functions of PoLiS and HDD (PoLiSmin and HDDmin) provided better results, only these were used in this test. Based on the generated deviations, the optimal thresholds were determined as shown in Table 3.

Table 3. Optimal thresholds per deviation distance of generated errors.

\begin{tabular}{|c|c|c|c|c|c|}
\hline \multirow{2}{*}{$\begin{array}{c}\text { Deviation } \\
\text { Distance (m) }\end{array}$} & \multicolumn{5}{|c|}{ Optimal Threshold } \\
\hline & $C A R(\%)$ & $C B R(\%)$ & $\operatorname{IBR}(\%)$ & $H D D \min (\mathrm{m})$ & $\operatorname{PoLiSmin}(\mathrm{m})$ \\
\hline 0.25 & 78.6 & 73.6 & 72.3 & 7.4 & 1.10 \\
\hline 0.50 & 78.6 & 77.9 & 73.2 & 7.7 & 1.28 \\
\hline 0.75 & 77.1 & 77.8 & 72.7 & 8.9 & 1.47 \\
\hline 1.00 & 74.2 & 78.0 & 73.1 & 8.9 & 1.63 \\
\hline 1.25 & 72.9 & 77.2 & 74.5 & 8.3 & 1.55 \\
\hline 1.50 & 70.4 & 76.4 & 73.0 & 7.9 & 1.89 \\
\hline 1.75 & 70.0 & 74.4 & 73.0 & 7.8 & 2.09 \\
\hline 2.00 & 65.5 & 81.0 & 75.3 & 8.0 & 2.32 \\
\hline 2.25 & 62.1 & 79.6 & 75.2 & 7.6 & 2.46 \\
\hline 2.50 & 59.9 & 78.2 & 75.7 & 7.7 & 2.60 \\
\hline 2.75 & 59.0 & 77.3 & 76.2 & 8.3 & 2.77 \\
\hline 3.00 & 59.5 & 78.4 & 77.7 & 8.3 & 3.05 \\
\hline 3.25 & 58.7 & 77.6 & 75.3 & 8.9 & 3.17 \\
\hline 3.50 & 55.2 & 78.8 & 77.5 & 10.2 & 3.30 \\
\hline 3.75 & 57.3 & 76.6 & 74.0 & 8.3 & 3.43 \\
\hline 4.00 & 52.7 & 79.0 & 79.0 & 9.0 & 3.60 \\
\hline 4.25 & 51.1 & 76.5 & 76.3 & 8.9 & 3.77 \\
\hline 4.50 & 52.9 & 78.1 & 75.8 & 10.3 & 4.09 \\
\hline 4.75 & 48.8 & 78.6 & 75.2 & 11.9 & 4.31 \\
\hline 5.00 & 46.8 & 81.3 & 77.6 & 11.1 & 4.25 \\
\hline
\end{tabular}

Using the optimal threshold values in Table 3, the total errors were determined for the investigated matching methods. Figure 11 shows that for all matching methods the total error increases with increasing position deviation. At position deviations of $1.75 \mathrm{~m}$ or 
higher, the small advantages of $C B R$ and $I B R$ gradually decreased so that they converged with PoLiSmin. The offset between CAR and PoLiSmin, however, remained constant with increasing deviation. The total error of HDDmin increased comparatively less with increasing deviation, but showed generally lower accuracies.

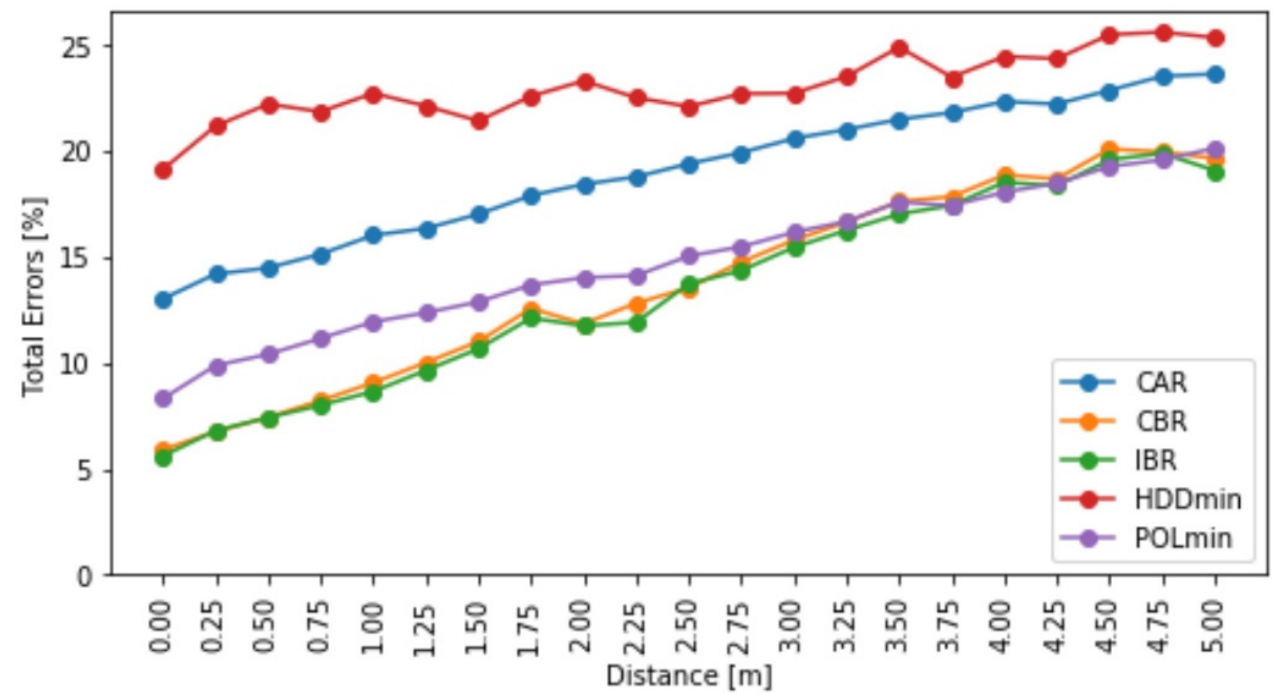

Figure 11. Total errors per distance of generated position deviations for distinguishing modified from replaced buildings.

\section{Discussion}

The results in Section 3.2 have shown that for the given study area, which contains footprints with a high positional accuracy of $\pm 1 \mathrm{~m}, C B R$ and $I B R$ are the most accurate matching methods to distinguish between modified and replaced buildings. The total error of $C B R$ and $I B R$ is $5.9 \%$ and $5.6 \%$, respectively, with optimal thresholds of $72 \%$ and $74 \%$. With regard to the first research question (RQ1), these thresholds are slightly above expectations, but this is probably due to the precision of the data source. However, these thresholds are not far from Rutzinger's assumption, which estimated a range up to $70 \%$ for most applications [38]. Compared to $C B R, I B R$ only provides better results when building demolition and expansion occur simultaneously in a modification. Since this is rarely the case in the given study area, the overall difference of IBR to CBR is minimal. The PoLiS metric has a total error of $12.7 \%$, which is about twice as large. The total error of CAR is about the same $(13.0 \%)$. HDD, in contrast, is less suitable for differentiation, since its total error is quite high $(25.3 \%)$. Avbelj also found that HDD is much more sensitive to deviations than PoLiS [14], which is consistent with our findings.

In addition, it was shown in Section 3.2 that to distinguish modification from replacement, the minimum functions of PoLiS and HDD (PoLiSmin and HDDmin) are more accurate than the maximum functions, thus answering the second research question (RQ2). PoLiSmin has a total error of $8.3 \%$ which is not a big difference from that of CBR and IBR. On the other hand, HDDmin has a total error of $19.1 \%$, which is quite inaccurate.

To address the third research question of how position deviations affect accuracy (RQ3), we generated random position deviations. In Section 3.3. we have shown that PoLiSmin converges to the accuracies of CBR and IBR from a deviation of $1.75 \mathrm{~m}$ and greater. This confirmed our assumption in research question 3 that with increasing position deviation, $C B R$ and $I B R$ are less suitable for differentiation due to the tolerance ranges. At a deviation of $2.75 \mathrm{~m}, C B R, I B R$ and PoLiS reach a total error of $15 \%$, which is considered insufficiently accurate. Thereby, for $C A R$, a threshold value in the range of $78.6 \%$ to $46.8 \%$ was obtained with increasing deviation, which is similar to Rutzinger's observation of $70 \%$ to $50 \%$ [38]. For $C B R$ and $I B R$, on the other hand, the threshold value increased with increasing deviation, so that the threshold values for the original data (no additional 
deviation) were $72 \%$ and $74 \%$, respectively, whereas for higher deviation $( \pm 5 \mathrm{~m})$ these were about $81 \%$ and $78 \%$. However, the range of these thresholds is much smaller compared to CAR. For PoLiSmin, the determined thresholds are very similar to the position deviation (given standard deviation of $\pm 1 \mathrm{~m}$ plus additional generated deviation), which is an advantage when the standard deviation is known.

Overall, it can be said that $C B R$ and $I B R$ are the more accurate methods for distinguishing between modified and replaced buildings for position deviations up to $1.75 \mathrm{~m}$. Since $C B R$ needs about half the computation time of $I B R$, it is preferred. A significant advantage of PoLiSmin and HDDmin is that no additional parameters, such as the buffer tolerance $(\varepsilon)$ as in $C B R$ and $I B R$, are required. If different data sources with different or unknown position accuracies are compared, PoLiSmin is therefore also recommended. In addition, PoLiSmin requires half the computation time of $C B R$ (and a quarter of that of $I B R$ ), which is advantageous for larger datasets. $C A R$ and $H D D$, on the other hand, are not recommended due to the high level of inaccuracies even with small position deviations.

To be able to detect unchanged (identical) buildings, the unadjusted PoLiS metric would be more useful than PoLiSmin. The thresholds at which a building can be considered unchanged would need to be determined in another study.

\section{Conclusions}

In this paper we have investigated how well building modifications can be distinguished from replaced buildings based on vector geometries. For this purpose, we examined 2285 building pairs based on dataset changes in a large study area in Hamburg.

We manually determined via aerial images whether the nonidentical building pairs were altered (modified) buildings or demolished and newly constructed buildings (replacement buildings), which served as a reference. Using this reference data, we examined various matching methods and determined their accuracy as well as the optimal thresholds for distinguishing between modified and replacement buildings.

We found that the matching methods of Common Area Ratio (CAR), Hausdorff Distance $(H D D)$ and Point Line Segments (PoLiS) are less suitable for distinguishing between modification and replacement, because the building pairs contained too many changes (total error: $13.0 \%, 25.3 \%$ and $12.7 \%$, respectively). In contrast, the line-based matching methods of Common Boundary (CBR) and the Intersection Boundary Ratio (IBR), which we developed, were able to produce much more accurate results (total error: $5.9 \%$ and $5.6 \%$, respectively).

HDD and PoLiS are very sensitive to changes, and, as we investigated nonidentical pairs of buildings, we tested these methods to determine whether a minimum function is better suited for differentiation. For PoLiSmin, better results were obtained (total error: $8.3 \%$ ), which was not the case for HDDmin (total error: $19.1 \%$ ).

Since the underlying dataset was very accurate, we also investigated how much position deviations affect the accuracies, which should allow transferability to less well-matched datasets. To address this question, we developed a novel method to generate position deviations. In addition, the threshold values determined in this test can be used as a basis for other investigations. We gradually shifted the line segments laterally in a range of 0 to $5 \mathrm{~m}$, with the position offset following a Gaussian normal distribution. This showed that up to a position offset of $1.75 \mathrm{~m}, C B R$ and IBR have the best accuracies. However, the minimum function of PoLiS is comparable and achieves the same accuracies as the two previously mentioned methods from $2.75 \mathrm{~m}$ and higher. For larger position deviations, however, the methods have a total error of over $15 \%$ and are therefore increasingly inaccurate.

Author Contributions: Conceptualization, Martin Schorcht and Robert Hecht; methodology, Martin Schorcht; software, Martin Schorcht; validation, Martin Schorcht; writing — original draft preparation, Martin Schorcht; writing-review and editing, Robert Hecht and Gotthard Meinel; supervision, Robert Hecht and Gotthard Meinel; All authors have read and agreed to the published version of the manuscript.

Funding: This research received no external funding. 
Institutional Review Board Statement: Not applicable.

Informed Consent Statement: Not applicable.

Data Availability Statement: The LoD1 data used in this study are openly available at Transparenzportal Hamburg (https:/ / transparenz.hamburg.de/, accessed on 19 November 2021), from Freie und Hansestadt Hamburg, Landesbetrieb Geoinformation und Vermessung (LGV), in compliance with the license dl-de/by-2-0: LoD1 dataset Hamburg 2015: https://daten-hamburg.de/ geographie_geologie_geobasisdaten/3d_stadtmodell_lod1/LoD1_HH_2015-03-25.zip (accessed on 15 November 2021). LoD1 dataset Hamburg 2018: https:/ / daten-hamburg.de/geographie_geologie_ geobasisdaten/3d_stadtmodell_lod1/LoD1-DE_HH_2018-03-23.zip (accessed on 15 November 2021). The resulting dataset used in this study is openly available on FigShare at https:/ /dx.doi.org/10.608 4/m9.figshare.18027683 (accessed on 3 December 2021), in compliance with the license dl-de/by-2-0 of Freie und Hansestadt Hamburg, Landesbetrieb Geoinformation und Vermessung (LGV).

Conflicts of Interest: The authors declare no conflict of interest.

\section{References}

1. Biljecki, F.; Stoter, J.; Ledoux, H.; Zlatanova, S.; Çöltekin, A. Applications of 3D City Models: State of the Art Review. ISPRS Int. J. Geo-Inf. 2015, 4, 2842-2889. [CrossRef]

2. Evans, S.; Liddiard, R.; Steadman, P. 3DStock: A New Kind of Three-Dimensional Model of the Building Stock of England and Wales, for Use in Energy Analysis. Environ. Plan. B Urban Anal. City Sci. 2017, 44, 227-255. [CrossRef]

3. Vanderhaegen, S.; Canters, F. Mapping Urban Form and Function at City Block Level Using Spatial Metrics. Landsc. Urban Plan. 2017, 167, 399-409. [CrossRef]

4. Biljecki, F.; Ohori, K.A.; Ledoux, H.; Peters, R.; Stoter, J. Population Estimation Using a 3D City Model: A Multi-Scale CountryWide Study in the Netherlands. PLoS ONE 2016, 11, e0156808. [CrossRef]

5. Broitman, D.; Koomen, E. The Attraction of Urban Cores: Densification in Dutch City Centres. Urban Stud. 2020, 57, 1920-1939. [CrossRef]

6. Hecht, R.; Herold, H.; Behnisch, M.; Jehling, M. Mapping Long-Term Dynamics of Population and Dwellings Based on a Multi-Temporal Analysis of Urban Morphologies. ISPRS Int. J. Geo-Inf. 2019, 8, 2. [CrossRef]

7. Khanal, N.; Uddin, K.; Matin, M.A.; Tenneson, K. Automatic Detection of Spatiotemporal Urban Expansion Patterns by Fusing OSM and Landsat Data in Kathmandu. Remote Sens. 2019, 11, 2296. [CrossRef]

8. Ghamisi, P.; Rasti, B.; Yokoya, N.; Wang, Q.; Hofle, B.; Bruzzone, L.; Bovolo, F.; Chi, M.; Anders, K.; Gloaguen, R.; et al. Multisource and Multitemporal Data Fusion in Remote Sensing: A Comprehensive Review of the State of the Art. IEEE Geosci. Remote Sens. Mag. 2019, 7, 6-39. [CrossRef]

9. Dai, C.; Zhang, Z.; Lin, D. An Object-Based Bidirectional Method for Integrated Building Extraction and Change Detection between Multimodal Point Clouds. Remote Sens. 2020, 12, 1680. [CrossRef]

10. Sester, M.; Brenner, C. Datenquellen Und Methoden Für Eine Automatische Bestimmung von Gebäude- Und Siedlungsvolumen; Institute of Cartography and Geoinformatics—Leibniz University Hannover: Hannover, Germany, 2002.

11. Matikainen, L.; Hyyppä, J.; Ahokas, E.; Markelin, L.; Kaartinen, H. Automatic Detection of Buildings and Changes in Buildings for Updating of Maps. Remote Sens. 2010, 2, 1217-1248. [CrossRef]

12. Jabari, S.; Zhang, Y. Building Change Detection Using Multi-Sensor and Multi-View- Angle Imagery. IOP Conf. Ser. Earth Environ. Sci. 2016, 34, 012018. [CrossRef]

13. Gergelova, M.B.; Labant, S.; Kuzevic, S.; Kuzevicova, Z.; Pavolova, H. Identification of Roof Surfaces from LiDAR Cloud Points by GIS Tools: A Case Study of Lučenec, Slovakia. Sustainability 2020, 12, 6847. [CrossRef]

14. Avbelj, J.; Muller, R.; Bamler, R. A Metric for Polygon Comparison and Building Extraction Evaluation. IEEE Geosci. Remote Sens. Lett. 2015, 12, 170-174. [CrossRef]

15. Fu, Z.; Fan, L.; Yu, Z.; Zhou, K. A Moment-Based Shape Similarity Measurement for Areal Entities in Geographical Vector Data. ISPRS Int. J. Geo-Inf. 2018, 7, 208. [CrossRef]

16. Rottensteiner, F.; Sohn, G.; Gerke, M.; Wegner, J.D.; Breitkopf, U.; Jung, J. Results of the ISPRS Benchmark on Urban Object Detection and 3D Building Reconstruction. ISPRS J. Photogramm. Remote Sens. 2014, 93, 256-271. [CrossRef]

17. Wu, J.; Wan, Y.; Chiang, Y.; Fu, Z.; Deng, M. A Matching Algorithm Based on Voronoi Diagram for Multi-Scale Polygonal Residential Areas. IEEE Access 2018, 6, 4904-4915. [CrossRef]

18. Yang, M.; Ai, T.; Yan, X.; Chen, Y.; Zhang, X. A Map-Algebra-Based Method for Automatic Change Detection and Spatial Data Updating across Multiple Scales. Trans. GIS 2018, 22, 435-454. [CrossRef]

19. Zhang, Y.; Huang, J.; Deng, M.; Chen, C.; Zhou, F.; Xie, S.; Fang, X. Automated Matching of Multi-Scale Building Data Based on Relaxation Labelling and Pattern Combinations. ISPRS Int. J. Geo-Inf. 2019, 8, 38. [CrossRef]

20. Carleer, A.P.; Wolff, E. Change Detection for Updates of Vector Database through Region-Based Classification of VHR Satellite Data. In Remote Sensing for Environmental Monitoring, GIS Applications, and Geology VII; International Society for Optics and Photonics: Bellingham, WA, USA, 2007; Volume 6749. 
21. Qin, R. Change Detection on LOD 2 Building Models with Very High Resolution Spaceborne Stereo Imagery. ISPRS J. Photogramm. Remote Sens. 2014, 96, 179-192. [CrossRef]

22. Abdessetar, M.; Zhong, Y. Buildings Change Detection Based on Shape Matching for Multi-Resolution Remote Sensing Imagery. ISPRS Int. Arch. Photogramm. Remote Sens. Spat. Inf. Sci. 2017, XLII-2/W7, 683-687. [CrossRef]

23. Hartmann, A.; Meinel, G.; Behnisch, M.; Hecht, R. Gebäudebestandsmonitoring-Prozessierungsschritte für den Aufbau homogener Gebäudedatensätze. Flächensparen Ökosystemleistungen Handl. 2016, 69, 203-214.

24. Meinel, G.; Krüger, T. Methodik eines Flächennutzungsmonitorings auf Grundlage des ATKIS-Basis-DLM. J. Cartogr. Geogr. Inf. 2014, 64, 324-331. [CrossRef]

25. EEA. Urban Sprawl in Europe-Joint EEA-FOEN Report-European Environment Agency; Publications Office of the European Union: Luxembourg, 2016. Available online: https:// data.europa.eu/doi/10.2800/143470 (accessed on 1 December 2021).

26. DESTATIS. Qualitätsbericht_Flächenerhebung Nach Art der Tatsächlichen Nutzung; Statistisches Bundesamt (Destatis): Wiesbaden, Germany, 2018.

27. Deutsche Bundesregierung. Die Deutsche Nachhaltigkeitsstrategie-Aktualisierung 2018; Presse-und Informationsamt der Bundesregierung: Berlin, Germany, 2018.

28. Biljecki, F.; Ledoux, H.; Stoter, J. An Improved LOD Specification for 3D Building Models. Comput. Environ. Urban Syst. 2016, 59, 25-37. [CrossRef]

29. Kaden, R.; Kolbe, T.H. City-Wide total energy demand estimation of buildings using semantic 3D city models and statistical data. In Proceedings of the ISPRS Annals of the Photogrammetry, Remote Sensing and Spatial Information Sciences, Istanbul, Turkey, 27-29 November 2013; Volume II-2-W1, pp. 163-171.

30. Zhang, X.; Stoter, J.; Ai, T.; Kraak, M.-J.; Molenaar, M. Automated Evaluation of Building Alignments in Generalized Maps. Int. J. Geogr. Inf. Sci. 2013, 27, 1550-1571. [CrossRef]

31. Brovelli, M.A.; Zamboni, G. A New Method for the Assessment of Spatial Accuracy and Completeness of OpenStreetMap Building Footprints. ISPRS Int. J. Geo-Inf. 2018, 7, 289. [CrossRef]

32. Qin, R.; Tian, J.; Reinartz, P. 3D Change Detection-Approaches and Applications. ISPRS J. Photogramm. Remote Sens. 2016, 122, 41-56. [CrossRef]

33. Fan, H.; Zipf, A.; Fu, Q.; Neis, P. Quality Assessment for Building Footprints Data on OpenStreetMap. Int. J. Geogr. Inf. Sci. 2014, 28, 700-719. [CrossRef]

34. Pedrinis, F.; Morel, M.; Gesquière, G. Change Detection of Cities. In 3D Geoinformation Science; Lecture Notes in Geoinformation and Cartography; Springer: Cham, Switzerland, 2015. [CrossRef]

35. Zhou, X.; Chen, Z.; Zhang, X.; Ai, T. Change Detection for Building Footprints with Different Levels of Detail Using Combined Shape and Pattern Analysis. ISPRS Int. J. Geo-Inf. 2018, 7, 406. [CrossRef]

36. Schowengerdt, R.A. Remote Sensing: Models and Methods for Image Processing; Academic Press: Cambridge, MA, USA, 2006; ISBN 978-0-08-048058-9.

37. Ghani, N.L.A.; Abidin, S.Z.Z. The Classification of Urban Growth Pattern Using Topological Relation Border Length Algorithm: An Experimental Study. In Recent Trends in Information and Communication Technology; Saeed, F., Gazem, N., Patnaik, S., Saed Balaid, A.S., Mohammed, F., Eds.; Springer International Publishing: Cham, Switzerland, 2018; pp. 545-553.

38. Rutzinger, M.; Rottensteiner, F.; Pfeifer, N. A Comparison of Evaluation Techniques for Building Extraction From Airborne Laser Scanning. IEEE J. Sel. Top. Appl. Earth Obs. Remote Sens. 2009, 2, 11-20. [CrossRef]

39. Veltkamp, R. Shape Matching: Similarity Measures and Algorithms. In Proceedings of the International Conference on Shape Modeling and Applications, Genova, Italy, 7-11 May 2001; pp. 188-197.

40. AdV. Produktstandard für 3D-Gebäudemodelle Version 1.4; Arbeitsgemeinschaft der Vermessungsverwaltungen der Länder der Bundesrepublik Deutschland (AdV): Munich, Germany, 2017; p. 6.

41. Cai, L.; Shi, W.; Miao, Z.; Hao, M. Accuracy Assessment Measures for Object Extraction from Remote Sensing Images. Remote Sens. 2018, 10, 303. [CrossRef] 